\title{
Transparent Conducting Polymer/Nitride Semiconductor Heterojunction Solar Cells
}

\author{
Nobuyuki Matsuki1,3, Yoshitaka Nakano², Yoshihiro Irokawa1, \\ Mickael Lozac' $\mathrm{h}^{1}$ and Masatomo Sumiya ${ }^{1}$ \\ ${ }^{1}$ National Institute for Materials Science, Namiki, Tsukuba, Ibarak, \\ Institute of Science and Technology Research, \\ Chubu University, Matsumoto, Kasugai, Aichi, \\ ${ }^{3}$ Department of Electrical and Electronic Engineering, \\ Faculty of Engineering, Gifu University, Yanagido, Gifu, \\ Japan
}

\section{Introduction}

Energy supplies that depend on fossil fuels evoke significant concern about the future depletion of those resources and the emission of carbon dioxide and sulfidizing gas, which are believed to cause environmental problems including climate change and acid precipitation (Solomon et al., 2007). Solar cells, which convert sunlight directly to electric power, are one of the most promising devices for a clean and enduring energy source. The standard energy-weighted power density of sunlight, which is defined as air mass 1.5 , is $1 \mathrm{~kW} / \mathrm{m}^{2}$ under clear and sunny weather conditions (Myers et al., 2000). The maximum available amount of sunlight is usually lower than the value described above due to the weather and the total hours of sunlight in the region.

Thus, the first important aim for developing a solar cell is to derive the highest possible photovoltaic conversion efficiency from the utilized materials and structure. When a solar cell with a single bandgap, $E_{\mathrm{g}}$, is exposed to the solar spectrum, a photon with less energy than $E_{\mathrm{g}}$ does not contribute to the cell output. Therefore, a multilayer structure comprising a variety of bandgaps is effective for the collection of photons in a wide range of the solar spectrum.

The current (2010) best research-cell efficiencies of typical solar cells are as follows (Green, 2010): crystalline Si (25.0\%), multicrystalline Si (20.4\%), crystalline GaAs (26.4\%), CuInGaSe $(19.4 \%)$, CdTe (16.7\%), amorphous Si $(10.1 \%)$, dye-sensitized polymers $(10.4 \%)$, and organic polymers $(5.15 \%)$. In addition to these, there have been a number of studies focused on developing "third-generation photovoltaics" with ultra-high conversion efficiencies at a low cost (Green, 2001). More recently, after the discovery of the wide band gap range of 0.65-3.4 $\mathrm{eV}$ in $\mathrm{In}_{\mathrm{x}} \mathrm{Ga}_{1-\mathrm{x}} \mathrm{N}$, this material is considered to be one of the most promising candidates for third-generation photovoltaic cells. 
Aiming at developing multijunction solar cells based on III-nitrides, we have focused on the potential of a transparent conductive polymer (TCP) as a UV-transparent window layer for the cell instead of adopting the conventional all-inorganic p-i-n structure. In this chapter, we describe the concept and experimental results of the development of $\mathrm{TCP} /$ nitride semiconductor heterojunction solar cells. In addition, prospects for their further development are discussed.

\section{Basic concepts}

\subsection{Background}

In 2002, an epochal report on the $E_{\mathrm{g}}$ of $\mathrm{InN}$ was published; the $E_{\mathrm{g}}$, which had been believed to be $2.0 \mathrm{eV}$ for many years, was found to be less than $1.0 \mathrm{eV}$ by photoluminescence characterization (Matsuoka et al., 2002). Subsequent investigations verified that the correct $E_{\mathrm{g}}$ is $0.7 \mathrm{eV}$ (Wu et al., 2003). This fact immediately impelled III-nitride-researchers to consider applying III-nitrides to solar cells because $\operatorname{In}_{x} \mathrm{Ga}_{1-\mathrm{x}} \mathrm{N}$, which is the III-nitride compound obtained from $\operatorname{InN}\left(E_{\mathrm{g}}=0.7 \mathrm{eV}\right)$ and $\mathrm{GaN}\left(E_{\mathrm{g}}=3.4 \mathrm{eV}\right)$, is a direct transition semiconductor that would widely cover the solar spectrum. Furthermore, the strong Piezoelectric-field that forms in III-nitride semiconductors, which is a critical problem for optical emission devices due to the suppression of carrier recombination (Takeuchi, 1998), will be more advantageous to photovoltaic devices in which carrier separation is necessary. There have been reports on the theoretical predictions of the conversion efficiency of $\operatorname{In}_{x} \mathrm{Ga}_{1-\mathrm{x}} \mathrm{N}$ solar cells that suggest that the maximum conversion efficiency of $\operatorname{In}_{x} \mathrm{Ga}_{1-\mathrm{x}} \mathrm{N}$ solar cells will reach 35-40\% (Hamzaoui, 2005; Zhang, 2008). Experimental results of $\operatorname{In}_{\mathrm{x}} \mathrm{G}_{\mathrm{a1}-\mathrm{x}} \mathrm{N}$-based solar cells have been also reported (Chen, 2008; Zheng, 2008; Dahal, 2009; Kuwahara, 2010). Although the potential conversion efficiency of $\operatorname{In}_{x} \mathrm{Ga}_{1-x} \mathrm{~N}$ solar cells is promisingly high, the highest one so far obtained through an InGaN/InGaN superlattice structure remains as low as $2.5 \%$ (Kuwahara, 2011).

The challenges for the development of high efficiency InGaN solar cells are mainly attributed to the necessity for: (1) a conductive crystalline substrate to grow high quality nitride layers in order to reduce series resistance, (2) a high quality film growth technique to reduce carrier recombination, (3) high-efficiency p-type doping, and (4) a novel cell design that allows absorption in a wide range of the solar spectrum and efficient collection of the photo-generated carrier.

Our research has targeted issues (3) and (4) above by introducing a novel Schottky contact consisting of a transparent conducting polymer/nitride semiconductor heterojunction. In this section, the advantages of the polymer/nitride semiconductor heterojunction are described in comparison with those of a conventional nitride $p$-n homojunction. In addition, the optical and electrical properties of the transparent conducting polymers are shown.

\subsection{Issues with solar cell window layer}

Figure 1 shows a schematic structure of the $\operatorname{In}_{x} \mathrm{Ga}_{1-x} \mathrm{~N}$-based solar cell that exhibits $2.5 \%$ conversion efficiency (Kuwahara, 2011). Due to the low doping efficiency and activity of $\mathrm{Mg}$ in p-type III nitride semiconductors, the $\mathrm{In}_{\mathrm{x}} \mathrm{Ga}_{1-\mathrm{x}} \mathrm{N}$-based solar cell requires a highly conductive front layer on top of the p-type layer to collect the photo-generated carriers. 


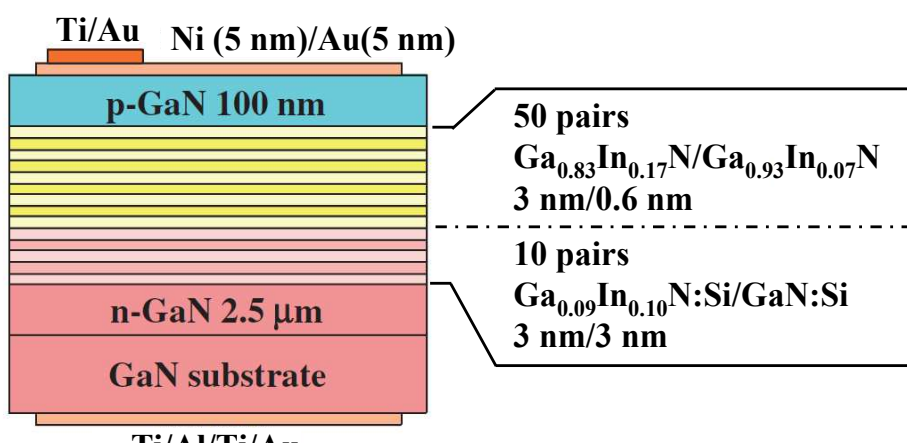

$\mathbf{T i} / \mathbf{A l} / \mathbf{T i} / \mathbf{A u}$

Fig. 1. Schematic of $\operatorname{In}_{x} \mathrm{Ga}_{1-x} \mathrm{~N}$-based solar cell exhibiting $2.5 \%$ conversion efficiency (Kuwahara, 2011).

In Figure 1, the electrode on the window side consists of a Ni/Au semitransparent thin film similar to that in the conventional III-nitride-based photoelectric devices. Despite the transparency of the Ni/ Au thin-film being as low as $67 \%$, this material is utilized because it forms good ohmic contact with the III-nitride semiconducting layer (Song et al., 2010). With the aim of increasing the transparency of the window-side electrode, indium tin oxide (ITO) was applied to a III-nitride light-emitting diode (LED) (Shim et al, 2001; Chang et al., 2003). In the same study, although the light emitting intensity in the ITO/GaN LED was enhanced compared with that of a Ni/Au/GaN LED under the same current density, the lifetime of the device was significantly shortened due to the heat generated by the high contact resistance between ITO and GaN. Thus, ITO is not a suitable alternative candidate for the metal semitransparent layer unless the contact resistance problem is solved. The low optical transparency and/or the high contact resistance of the front conductive layer are a critical disadvantage for solar cell applications; therefore, new materials that can overcome these issues are highly desirable.

\subsection{Conducting polymers as electrodes}

Recently, the electronic properties of conducting polymers have been significantly improved and they have been extensively applied in various electric devices (Heeger, 2001).

The study of polymers began with the accidental discovery of vinyl chloride by $\mathrm{H}$. V. Regnault (1835). Thereafter, various kinds of polymers were found and industrialized including ebonite (1851), celluloid (1856), bakelite (1907), polyvinyl chloride (1926), polyethylene (1898; 1933), nylon (1935), etc. Polymers show good electrical insulating properties due to the lack of free electrons; therefore, they have been extensively applied as electrical insulators. However, in 1963, D. E. Weiss and his colleagues discovered that polypyrrole became electrically conductive by doping it with iodine (Bolto et al., 1963). In 1968, H. Shirakawa and his colleagues accidentally discovered a fabrication process for thinfilm polyacetylene. In 1975, A. G. MacDiamid noticed the metallic-colored thin-film polyacetylene when he visited Shirakawa's laboratory. Thereafter, collaborative works by A. Heeger, A. G. MacDiamid, and H. Shirakawa began and soon they found a remarkable effect that the electrical conductivity of the polyacetylene thin-film increased over seven 
orders of magnitude, from $3.2 \times 10^{-6}$ to $3.8 \times 10^{2} \Omega^{-1} \mathrm{~cm}^{-1}$, with iodine doping (Shirakawa et al., 1977). Since these early studies, various sorts of $\pi$-conjugated polymer thin films have been produced and efforts to improve their conductivity have been made.

We briefly describe the origin of conductivity in degenerate $\pi$-conjugated polymers below (Heeger, 2001). In degenerate $\pi$-conjugated polymers, stable charge-neutral-unpairedelectrons called solitons exist due to defects at the counterturned connection of the molecular chain. When the materials are doped with acceptor ions like $I_{2}$, the acceptor ion abstracts an electron from the soliton; then the neutral soliton turns into a positivelycharged soliton while $\mathrm{I}_{2}$ becomes $\mathrm{I}_{3}$. If the density of the positively-charged solitons is low, the positively-charged soliton tends to pair with a neutral soliton to form a polaron. The polaron is mobile along the polymer chain, thus it behaves as a positive charge. However, the mobility of the polaron is quite low due to the effect of Coulomb attraction induced by the counterion $\left(\mathrm{I}_{3}^{-}\right)$. The Coulomb attraction is reduced by increasing the density of the counterions, which block the electric field. Thus, a high doping concentration of up to $\sim 20 \%$ is required to gain high conductivity of over $10^{2} \Omega^{-1} \mathrm{~cm}^{-1}$. Typical conducting polymers that have high conductivity are fabricated based on polyacetylene (PA), polythiophene (PT), polypyrrole (PPy), polyethylenedioxythiophene (PEDOT), and polyaniline (PANI) (Heeger, 2001).

\subsection{Transparent conducting polymers as Schottky contacts}

Among the various kinds of conducting polymers, we have focused primarily on polyaniline (PANI) and poly(ethylenedioxythiophene)-polystyrene sulfonate (PEDOT:PSS) because of their high conductivity $\left(\sim 1000 \Omega^{-1} \mathrm{~cm}^{-1}\right)$ and high optical transparency $(>80 \%)$ (Lee et al., 2006; Ha, 2004). Conducting polymers with high optical transparency are known as transparent conducting polymers (TCPs). PANI and PEDOT:PSS also have the advantage in a high workfunction of 5.2-5.3 eV (Brown, 1999; Jang, 2008). This workfunction value is comparable to that of $\mathrm{Ni}(5.1 \mathrm{eV})$ and $\mathrm{Au}(5.2 \mathrm{eV})$. The high workfunction properties of PANI and PEDOT:PSS make them feasible candidates as hole injection layers in polymer light emitting devices (Jang, 2008). If we assume that a heterojunction consists of a metallic layer and an n-type semiconductor, it is expected that electric barrier, or Schottky barrier, will form at the metal-semiconductor interface. The ideal Schottky barrier height, $\phi_{B}$, is given by following equation (Schottky, 1939; Mott, 1939):

$$
q \phi_{B}=q\left(\phi_{m}-\chi\right)
$$

where $q$ is the unit electronic charge, $\phi_{m}$ is the workfunction of the metallic material, and $\chi$ is the electron affinity of the semiconductor. In general, the experimentally observed Schottky barrier is modified due to the influence of image-force surface states of the semiconductor and/or the dipole effect (Tung, 2001; Kampen, 2006). Nevertheless, the ideal Schottky barrier height estimated from Eq. (1) is still useful to evaluate the potential barrier formation. There have been precedential reports on heterojunctions consisting of TCPs and inorganic monocrystalline semiconductors including: sulfonated-PANI/n-type Si (Wang et al., 2007; da Silva et al., 2009), PEDOT:PSS/SrTiO $3: \mathrm{Nb}$ (Yamaura et al., 2003), and PEDOT:PSS/ZnO (Nakano et al., 2008). The $\left(\phi_{m}-\chi\right)$ values of these TCP/semiconductor heterojunctions, and those of PEDOT:PSS or AIN with III-nitrides including AlN, GaN and InN, are summarized in Table 1. 


\begin{tabular}{|c|c|c|c|c|c|}
\hline \multicolumn{2}{|c|}{ TCP } & \multicolumn{2}{|c|}{ Semiconductor } & \multirow{2}{*}{$\begin{array}{l}\phi_{m}-\chi \\
(\mathrm{eV})\end{array}$} & \multirow[b]{2}{*}{ References } \\
\hline material & $\phi_{m}(\mathrm{eV})$ & material & $\chi(\mathrm{eV})$ & & \\
\hline \multirow{4}{*}{ PANI } & \multirow{4}{*}{$5.3 \mathrm{a}), \mathrm{b})$} & n-type Si & $4.05 \mathrm{c}), \mathrm{d})$ & $\overline{1.25}$ & a) Brown et al., 1999; \\
\hline & & AlN & $0.25 \mathrm{e})$ & 5.05 & b) Jang st al., 2008 \\
\hline & & $\mathrm{GaN}$ & $\left.3.3^{f}\right)$ & 2.0 & c) Wang et al, 2007 \\
\hline & & $\operatorname{InN}$ & $5.7 \mathrm{~g})$ & -0.4 & d) da Silva et al., 2009 \\
\hline \multirow{5}{*}{ PEDOT:PSS } & \multirow{5}{*}{$5.2 \mathrm{a}), \mathrm{b})$} & $\mathrm{SrTiO}_{3}: \mathrm{Nb}$ & $4.1^{\mathrm{h})}$ & $\overline{1.1}$ & e) Grabowski et al., 2001 \\
\hline & & $\mathrm{ZnO}$ & $4.3^{\mathrm{i})}$ & 0.7 & f) Wu et al., 1999 \\
\hline & & AlN & $0.25 \mathrm{e})$ & 4.95 & $\begin{array}{l}\text { g) Wu et al., } 2004 \\
\text { h) Yamaura, } 2003\end{array}$ \\
\hline & & $\mathrm{GaN}$ & $3.3^{f}$ & 1.9 & i) Nakano et al., 2008 \\
\hline & & InN & $5.7 \mathrm{~g})$ & -0.5 & \\
\hline
\end{tabular}

Table 1. Summary of workfunction barrier height properties of TCP/inorganic semiconductor heterojunction.

The theoretical Schottky barrier height $\left(\phi_{m}-\chi\right)$ is considerably high for AlN and GaN. Thus, it was expected that combinations of these TCPs and III-nitrides would exhibit highquality Schottky contact properties. When light is irradiated on the Schottky contact, the hole-electron pairs that are photo-generated in the depletion region of the semiconductor are separated due to the strong electric field. As a result, the carriers can be collected as a photocurrent. This suggests that the TCP Schottky contact can be a novel window layer for III-nitride solar cells as an alternative to a p-type layer. Based on this, we began to study transparent conducting polymer/nitride semiconductor heterojunction solar cells.

\section{Fabrication processes}

\subsection{Sample preparation for optical transmittance, workfunction, and conductivity characterizations}

Synthetic silica plates (500 $\mu \mathrm{m}$ thick) were utilized as the substrates to prepare samples for characterization to determine their optical transmittance, workfunction, and conductivity. A conductive polymer-dispersed solution of PEDOT:PSS (Clevios PH500, H. C. Starck; without dimethyl sulfoxide dopant) or PANI (ORMECON - Nissan Chemical Industries, Ltd.) was utilized to form the transparent conductive polymer films on the substrate. The same fabrication process was applied to both the PEDOT:PSS and PANI samples. The procedure was as follows:

1. The substrate $\left(2 \times 2 \mathrm{~cm}^{2}\right)$ was cleaned using ethanol and acetone for $5 \mathrm{~min}$ each in an ultrasonic cleaning bath at ambient temperature.

2. The cleaned substrate was set in a spin coater (MIKASA Ltd., 1H-D7), and the polymerdispersed solution were dropped onto the substrate using a dropper.

3. The substrate was spun at a $4000 \mathrm{rpm}$ rotating speed for $30 \mathrm{~s}$.

4. The drop and spin procedures were repeated 4 times in total to obtain a sufficient thickness.

5. The coated sample was baked in air at $130^{\circ} \mathrm{C}$ on an electric hotplate for $15 \mathrm{~min}$.

The resulting PEDOT:PSS and PANI film thicknesses were measured using a surface profilometer (Dektak 6M) and were found to be 420 and $170 \mathrm{~nm}$, respectively. In the spincoat process, we applied the same conditions to both the PEDOT:PSS and PANI samples. Their thicknesses unintentionally differed due to differences in the viscosities of their source solutions. 
In order to measure the conductivity, a coplanar electrode was fabricated by adding Ag paste to the TCP/synthetic silica plate sample. The electrode-gap width were both $3.3 \mathrm{~mm}$ and the lengths were 10.7 and $11.2 \mathrm{~mm}$, respectively, for the PEDOT:PSS and PANI samples.

\subsection{Transparent conducting polymer/nitride semiconductor heterojunction solar cells}

We fabricated a TCP/III-nitride heterojunction solar cell structure by employing PEDOT:PSS or PANI for the TCP layer and epitaxial GaN (epi.-GaN) for the III-nitride layer (Matsuki et al, 2009, 2010, 2011). Silicon-doped gallium nitride (GaN) was grown on a sapphire (0001) substrate (sapp (0001)) surface by typical metal-organic vapor-phase epitaxy (MOVPE). Ammonia and trimethylgallium were used as the $\mathrm{N}$ and Ga sources, respectively. Nitrogen was used as the carrier gas. An undoped buffer GaN layer with a thickness of 1 $\mu \mathrm{m}$ was deposited, followed by the growth of a $2 \mu \mathrm{m}$ thick Silicon-doped layer. The carrier concentration and electron mobility of the GaN film was determined to be $6.3 \times 10^{17} \mathrm{~cm}^{-3}$ and $360 \mathrm{~cm}^{2} / \mathrm{V} \cdot \mathrm{s}$, respectively, by Hall measurement.

The PEDOT:PSS or PANI thin film was formed on the epi.-GaN surface using the same process described in section 3.1. Then, in order to fabricate isolated cells, the TCP film was divided into several $\sim 3-9 \mathrm{~mm}^{2}$ square-shaped sections using a scratching tool. Finally, an ohmic contact for the GaN layer was made by soldering indium metal onto the area from which the TCP layer was removed. Figure 2 shows the schematic structure of the fabricated TCP/epi.-GaN heterojunction solar cell.

\section{Characterization methods}

\subsection{Photoemission electron spectroscopy for workfunction determination}

The workfunctions of the TCPs were determined using photoemission electron spectroscopy. The photoemission electron yield $Y$ is expressed as follows Kane (1962):

$$
Y=\alpha\left(h v-E_{t}\right)^{n}
$$

where $\alpha$ is a proportional constant, $h$ is Planck's constant, $v$ is the frequency, $E_{t}$ is the threshold energy, and the value of $n$ ranges from 1 to 5/2 depending on the system. For metallic materials, an $n$ value of 2 is recommended, and the $E_{t}$ is consistent with the

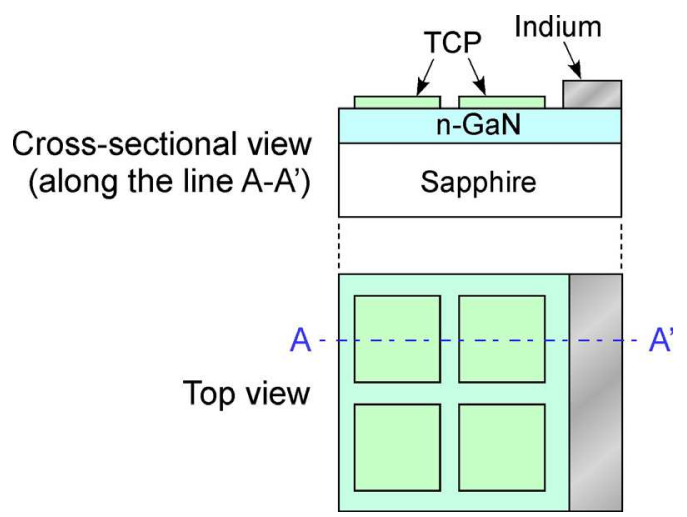

Fig. 2. Schematic of TCP/epi.-GaN sample. 
photoelectric workfunction. Thus, if we modify Eq. (2) to the following form (Eq. (2)'), we can determine $E_{t}$ by extrapolating the linear portion of a $Y^{1 / 2} \mathrm{vs} . h v$ plot:

$$
Y^{1 / 2}=\alpha\left(h v-E_{t}\right) .
$$

We employed a photoemission yield spectrometer (AC-3, Riken Keiki Co., Ltd.) to determine the workfunctions of the TCPs. The sample, which was prepared as described in section 3.1, was installed in the spectrometer and the photoemission yield was measured in air.

\subsection{Evaluation of current-voltage characteristics}

The diode (rectifying) and photovoltaic characteristics were evaluated using an electronic measurement system consisting of an electrometer and a light source. It is necessary for the diode characterization to cover a wide current range from $\sim 10^{-11}$ to $\sim 10^{-1}$ A to estimate the Schottky barrier height (SBH) based on the saturation current of the thermionic emission theory (Crowell, 1965). Thus, for the evaluation of the diode characteristics, we employed a high-precision electrometer with a built-in voltage source (Keithley 6487) and performed the measurement under dark conditions. The sample was put on a measurement stage and probe needles were connected to the indium and TCP parts. A xenon-arc light source (HX504/Q, Wacom Electric Co., Ltd.) was utilized for the evaluation of the photovoltaic characteristics. The light passed though an AM1.5 filter (Bunko Keiki Co., Ltd) and guided onto the TCP side by an aluminum mirror. The values for the source voltage and measured current were acquired by a computer through a GPIB-USB device (National Instruments Co. ltd.).

\subsection{Capacitance measurements}

The depletion layer width and built-in potential of the GaN layer in the TCP/GaN heterojunction solar cell were estimated using a capacitance measurement setup. A solartron 1255B frequency response analyzer was utilized for the measurement. The sample was set on a sample stage, which was in a vacuum chamber to avoid any influences from light and humidity.

\section{Experimental results and discussion}

\subsection{Conductivity, transparency, and workfunction of polyaniline and PEDOT:PSS}

The electrical conductivity was evaluated using a current-voltage $(I-V)$ measurement setup under dark conditions. The conductivities estimated from the result of the $I-V$ measurements were $3.4 \times 10^{2} \mathrm{~S} / \mathrm{cm}$ and $5.7 \times 10^{-1} \mathrm{~S} / \mathrm{cm}$ for PANI and PEDOT:PSS, respectively.

The optical transmittance was evaluated using a UV-visible-near-infrared spectrophotometer (UV-3150, Shimadzu Co., Ltd.). Figure 3(a) shows the optical transmittance spectra of the PEDOT:PSS and PANI films. Both of the films exhibited transmittance greater than $80 \%$ within the wavelength region between 250 and $1500 \mathrm{~nm}$. This is superior to conventional transparent contact materials such as transparent conductive oxides or semi-transparent metals (Kim et al., 2002; Satoh et al., 2007), which exhibit significant drops in transparency particularly near the UV region, as seen in Figure 3. 
The workfunctions of the TCPs were estimated using an ultraviolet photoelectron emission spectrometer (AC-3, Riken Keiki Co., Ltd.). Figure 3(b) depicts the photoelectron emission spectra of the PEDOT:PSS and PANI films. The spectra consist of two parts: one with a constant slope and another that linearly increases against the photon energy. The workfunction of PEDOT:PSS and PANI were found to be 5.3 and $5.2 \mathrm{eV}$, respectively, from Figure 3(b) by assuming that the threshold energy for photoelectron emission is located at the intersection point of the two straight lines that are fitted to the constant-slope and linearly-increasing-slope regions of the plots. These workfunction values show good agreement with those reported previously (Brown et al., 1999; Jang et al., 2008).

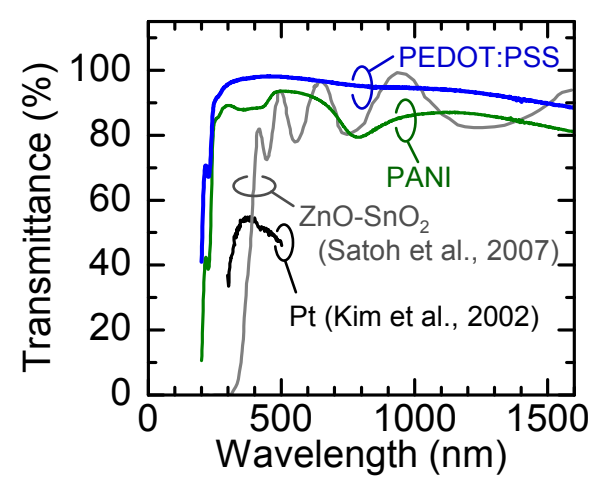

(a)

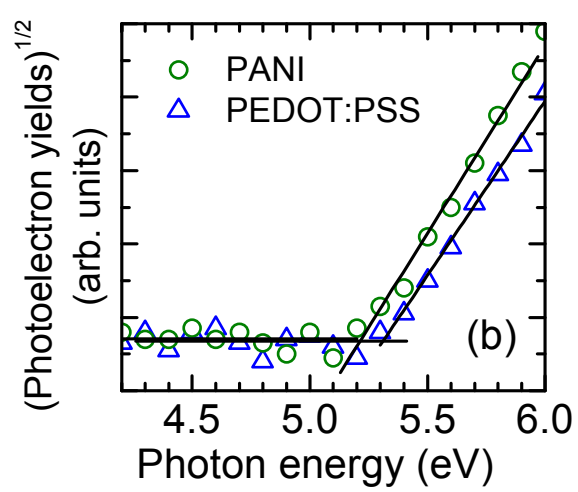

(b)

Fig. 3. (a) Optical transmittance spectra of PEDOT:PSS and PANI films. The transmittance

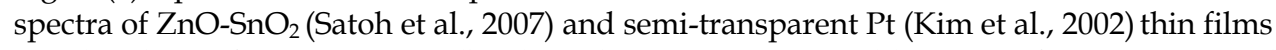
are also shown for comparison. (b) Photoelectron emission yield spectra of PEDOT:PSS and PANI films.

\subsection{Diode characteristics of transparent conducting polymer/nitride structures}

Figure 4(a) shows the current density-voltage $(J-V)$ characteristics of the TCP/epi.-GaN samples. The diode ideality factor, $n$, and the $\mathrm{SBH}, \phi_{\mathrm{B}}$, were evaluated by fitting the theoretical values obtained using the following equation based on the thermionic emission theory (Crowell, 1965):

$$
J=A * T^{2} \exp \left(-\frac{\phi_{B}}{k T}\right) \cdot\left[\exp \left(\frac{q V}{n k T}\right)-1\right]
$$

where $q$ is the electronic charge, $A^{*}$ represents the effective Richardson constant, which is defined as $A^{*} \equiv 4 \pi m_{e}^{*} k^{2} / h^{3} \quad\left(26.4 \mathrm{~A} /\left(\mathrm{cm}^{2} \cdot \mathrm{K}^{2}\right)\right.$ for $\left.\mathrm{GaN}\right), T$ is the absolute temperature, $k$ is the Boltzmann constant, $V$ is the applied bias, $m^{*}$ is the effective electron mass $\left(0.2 m_{e}\right.$ for $\mathrm{GaN})$, and $h$ is Planck's constant. The $\mathrm{n}$ and $\phi_{\mathrm{B}}$ values derived using the $J-V$ characteristics were 3.0 and $0.90 \mathrm{eV}$, respectively, for PEDOT:PSS/epi.-GaN, and 1.2 and $0.97 \mathrm{eV}$, respectively, for PANI/epi.-GaN. The low reverse leakage current, which ranged between $10^{-8}$ and $10^{-9} \mathrm{~A} / \mathrm{cm}^{2}$ at a reverse bias voltage of $-3 \mathrm{~V}$, indicates that the TCP/epi.-GaN 
heterojunctions had a Schottky contact property comparable to that exhibited by conventional metal Schottky contacts.

The depletion width, $W_{D}$, in the n-type $\mathrm{GaN}$ of the TCP/epi.-GaN heterojunction is expressed by

$$
W_{D}=\sqrt{\frac{2 \varepsilon_{S} \varepsilon_{0}}{q N_{D}}\left(V_{\text {Built-in }}-V\right)}
$$

where $\varepsilon_{S}$ is the relative dielectric constant of $\mathrm{GaN}$ and equals $8.9(\mathrm{Wu}, 2009), \varepsilon_{0}$ is the vacuum dielectric constant, $V_{\text {built-in }}$ is the built-in voltage formed in $\mathrm{GaN}, V$ is the bias voltage, and $N_{D}$ is the donor concentration. The space charge, $Q_{S C}$, in the depletion layer is given by $Q_{S C}=q N_{D} W_{D}$, thus, the depletion layer capacitance $C_{D}$ is obtained by

$$
C_{D}=\frac{\left|\partial Q_{S C}\right|}{\partial V}=\sqrt{\frac{q \varepsilon_{S} \varepsilon_{0} N_{D}}{2\left(V_{\text {built-in }}-V\right)}} .
$$

Equation (5) can also be written in the following form:

$$
\frac{1}{C_{D}^{2}}=\frac{2\left(V_{\text {built }- \text { in }}-V\right)}{q \varepsilon_{S} \varepsilon_{0} N_{D}}
$$

Equation (5)' suggests that if $1 / C_{D}^{2}$ exhibits linear plots against $V, V_{\text {built-in }}$ can be obtained at the $V$-intercept of extrapolated fit-line of the plots. Figure $4(\mathrm{~b})$ shows the plot of $1 / C_{D}^{2}$ as a function of the applied voltage. The frequencies used for the capacitance measurements were $100 \mathrm{~Hz}$ and $1 \mathrm{KHz}$ for the PANI/epi.-GaN and PEDOT:PSS/epi.-GaN heterojunctions, respectively. The frequency for measurement was chosen within a range that was sufficiently lower than the cut-off frequency, which is described in section 5.4. In Figure 4(b), both the data sets are linear and straight lines were successfully fitted to the data. The determined diode characteristics of the TCP/epi.-GaN heterojunction determined from the $J-V$ characteristics and capacitance measurements are summarized in Table 2 . The observed barrier height was comparable to that obtained by conventional metal Schottky contacts (Tracy et al., 2003). In the case of the conventional metal Schottky contacts, elaborate surface cleaning processes and moderate metal deposition in ultra-high-vacuum conditions are required to attain good Schottky contact with a $\phi_{B}$ of more than $1 \mathrm{eV}$. It is worth noting that the good Schottky contact properties in the TCP/epi.-GaN heterojunction were achieved with convenient spin coating of a water-dispersed TCP solution onto the GaN layer in air at ambient temperature.

The observed $\phi_{B}$ of the TCPs were much lower than expected from the energy difference $\phi_{m}-\chi$. There are various possibilities for the lower barrier heights including the Schottky effect, which is caused by the electronic mirror force, interface dipole effect, surface defects of GaN, inhomogeneous workfunctions in the TCP film, and/or residual contamination (Sze, 1981; Kampen, 2006). However, the major candidates for the modification of the barrier height have been discussed and are still controversial even in conventional metal/semiconductor Schottky heterojunctions (Tung, 2001). Further detailed investigation is required to determine which effects dominate in lowering the barrier in the $\mathrm{TCP} /$ epi.-GaN heterojunction. 


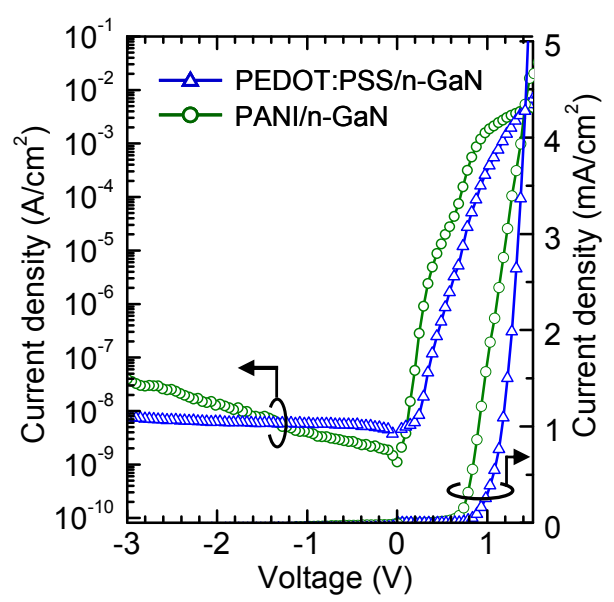

(a)

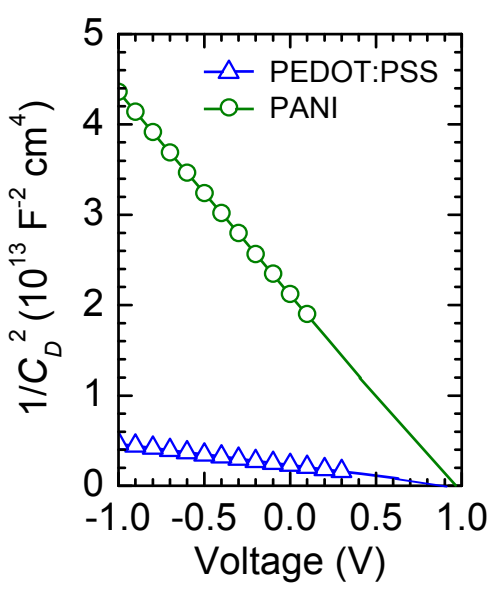

(b)

Fig. 4. (a) $J-V$ characteristics and (b) Capacitance-voltage plots of TCP/GaN heterojunction solar cells.

\begin{tabular}{|c|c|c|c|c|c|c|}
\hline & \multirow{2}{*}{$\begin{array}{l}\text { Polymer } \\
\text { thickness } \\
\quad(\mathrm{nm})\end{array}$} & \multirow{2}{*}{$\begin{array}{c}\text { Schottky } \\
\text { contact } \\
\text { area } \\
\left(\mathrm{mm}^{2}\right) \\
\end{array}$} & \multicolumn{2}{|c|}{$J-V$} & \multicolumn{2}{|c|}{$C-V$} \\
\hline & & & $n$ & $\begin{array}{c}\phi_{\mathrm{B}} \\
(\mathrm{eV})\end{array}$ & $\begin{array}{c}W_{D} \\
(\mathrm{~nm})\end{array}$ & $\begin{array}{c}V_{\text {Built-in }} \\
\text { (V) }\end{array}$ \\
\hline PANI & 170 & 7.1 & 1.2 & 0.97 & 39 & 0.94 \\
\hline PEDOT:PSS & 420 & 3.0 & 3.0 & 0.90 & 40 & 0.95 \\
\hline
\end{tabular}

Table 2. Diode characteristics of PEDOT:PSS/epi.-GaN (0001) and PANI/epi.-GaN.

\subsection{Photovoltaic characteristics of transparent conducting polymer/nitride semiconductor heterojunction solar cells}

Figure 5(a) shows the photovoltaic characteristics ( $J-V$ measurements under AM1.5 light irradiation) of the PANI/epi.-GaN and PEDOT:PSS/epi.-GaN samples. Table 3 represents a summary of the resulting photovoltaic and resistivity characteristics, which include opencircuit voltage $\left(V_{O C}\right)$, short-circuit current density $\left(J_{S C}\right)$, maximum output power $\left(P_{\max }\right)$, fill factor $(F F)$, shunt resistivity, and series resistivity. Note that the $V_{O C}$ exhibited high values $(>0.5 \mathrm{~V})$, which was much higher than the photovoltage observed in metal Schottky contacts on n-type GaN (Zhou et al., 2007) or PEDOT:PSS Schottky contacts on ZnO (Nakano et al., 2008). The superior photovoltages of the TCP/epi.-GaN heterojunctions are attributed to the following advantages conveyed by our process and substance properties: the ambient temperature fabrication resulted in less process damage and $\mathrm{GaN}$ exhibits less electron affinity (3.3 eV) than $\mathrm{ZnO}(4.4 \mathrm{eV})$ (Wu et al., 1999).

However, the rather small shunt resistivity and large series resistance that are observed, especially in the PANI/epi.-GaN heterojunction solar cell, are clearly due to the 
deterioration of $V_{O C}$ and FF. The optimization of the deposition process of TCP and introduction of a metal comb-shaped electrode on the TCP layer will improve $V_{O C}$ and $F F$. Figure 5(b) depicts external quantum efficiency of the PANI/epi.-GaN heterojunction solar cell. In order to visualize the capabilities of the photovoltaic device, the transmittance of PANI and the solar light intensity are also plotted as a function of wavelength.

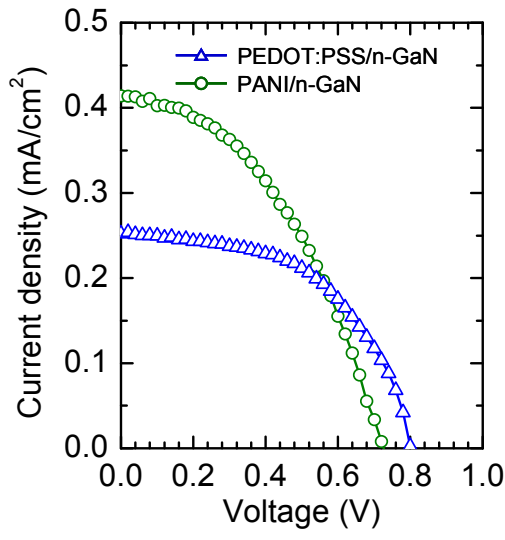

(a)

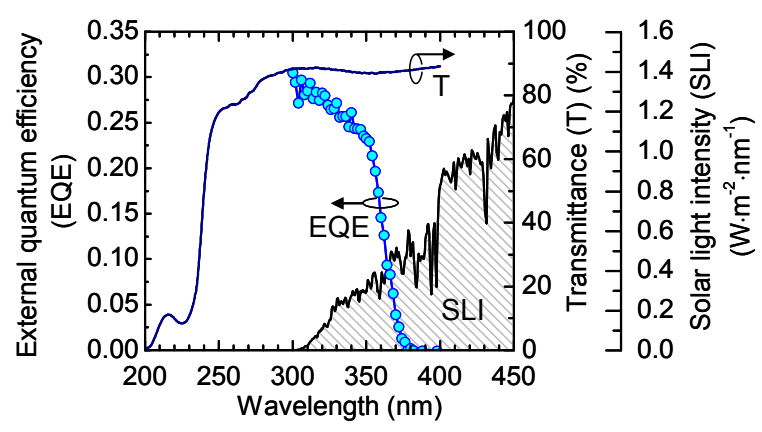

(b)

Fig. 5. (a) Photovoltaic characteristics of PANI/epi.-GaN and PEDOT:PSS/epi.-GaN heterojunction solar cells. (b) External quantum efficiency of PANI/epi.-GaN heterojunction solar cell, transmittance of PANI (T), and solar light intensity (SLI) as a function of wavelength.

\begin{tabular}{|c|c|c|c|c|c|c|c|c|}
\hline & \multirow{2}{*}{$\begin{array}{l}\text { Polymer } \\
\text { thickness } \\
(\mathrm{nm})\end{array}$} & \multirow{2}{*}{$\begin{array}{l}\text { Schottky } \\
\text { contact area } \\
\left(\mathrm{mm}^{2}\right)\end{array}$} & \multicolumn{4}{|c|}{ Photovoltaic characteristics } & \multicolumn{2}{|l|}{ Resistivity } \\
\hline & & & $\begin{array}{l}V_{O C} \\
(\mathrm{~V})\end{array}$ & $\begin{array}{c}J_{S C} \\
\left(\mathrm{~mA} / \mathrm{cm}^{2}\right)\end{array}$ & $F F$ & $\begin{array}{c}P_{\max } \\
\left(\mathrm{mW} / \mathrm{cm}^{2}\right)\end{array}$ & $\begin{array}{c}R_{s h} \\
\left(\mathrm{k} \Omega / \mathrm{cm}^{2}\right)\end{array}$ & $\begin{array}{c}R_{s} \\
\left(\Omega / \mathrm{cm}^{2}\right)\end{array}$ \\
\hline PANI & 170 & 7.1 & 0.73 & 0.41 & 0.42 & 0.13 & 21.2 & 310.3 \\
\hline PEDOT:PSS & 420 & 3.0 & 0.80 & 0.25 & 0.54 & 0.11 & 36.8 & 17.4 \\
\hline
\end{tabular}

Table 3. Photovoltaic characteristics of PEDOT:PSS/epi.-GaN and PANI/epi.-GaN.

\subsection{Frequency-dependent capacitance and its application to deep-level optical spectroscopy (DLOS)}

In this study, we found that the capacitance of the TCP/epi.-GaN heterojunction exhibits significant dependence on the frequency of measurement. Figure 6 shows the capacitancefrequency $(C-f)$ characteristics of the samples. The characteristics were measured under zero-bias conditions. As seen in the graph, the capacitance is constant at a lower frequency; however, it starts to drop at a specific frequency and then rapidly decreases towards the higher frequencies (cut-off). The frequencies at which the capacitance begins to drop are located at $\sim 20 \mathrm{~Hz}$ and $\sim 6 \mathrm{kHz}$ for the PEDOT:PSS/epi.-GaN and PANI/epi.-GaN samples, respectively. It is obvious that the difference in the specific frequencies between the two 
samples is due to differences in the intrinsic properties of the TCPs. Conductivity in TCPs is generated by a polaron in the $\pi$-conjugated bond; this polarized state causes a Debye-type dielectric dispersion response against an applied alternating electric field (Cole et al., 1941).

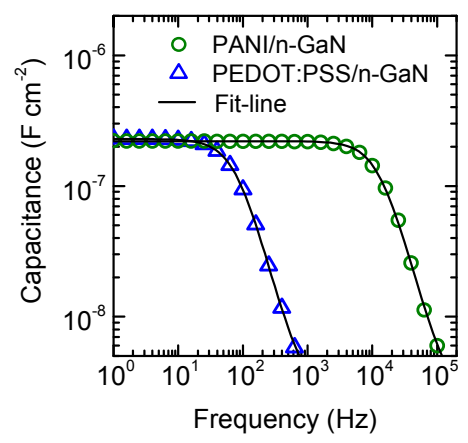

Fig. 6. C-f characteristics of TCP/epi.-GaN heterojunction solar cells.

Referring to a previous study on the frequency-dependent capacitance of PANI film (Mathai et al., 2002), the characteristics can be analyzed by assuming an equivalent circuit consisting of a frequency-independent capacitive element, $C_{0}$, in parallel with a resistive element, $R$, both in series with a constant low-value resistance. Based on this model, the frequencydependent capacitance of TCP, $C_{p}$, is given by the following equation:

$$
C_{p}=C_{0}+\frac{1}{(2 \pi f R)^{2} C_{0}}
$$

where $f$ is the applied bias frequency.

Furthermore, considering that the capacitance of the depletion layer, $C_{d}$, is in series with $C_{P}$, then the measured total capacitance of the sample, $C_{\text {total }}$, can be expressed by

$$
C_{\text {total }}=\frac{C_{p} \cdot C_{d}}{C_{p}+C_{d}} .
$$

The solid lines shown in Figure 5 represent the results of the least-square fit of the analytical curve produced based on Equations (6) and (7). The excellent fitting results indicate that the assumed model is adequate. The values of $R$ and $C_{0}$, which were derived from the fitting, were $5.3 \times 10^{2} \Omega$ and $2.1 \times 10^{-9} \mathrm{~F} \cdot \mathrm{cm}^{-2}$, respectively, for PANI/epi.-GaN and $8.4 \times 10^{4} \Omega$ and $2.3 \times 10^{-9} \mathrm{~F} \cdot \mathrm{cm}^{-2}$, respectively, for PEDOT:PSS/epi.-GaN. The large difference in the $R$ values between the two samples is reasonable if we take into account the large difference in the conductivity between PEDOT:PSS $\left(5.7 \times 10^{-1} \mathrm{~S} / \mathrm{cm}\right)$ and PANI $\left(3.4 \times 10^{2} \mathrm{~S} / \mathrm{cm}\right)$.

We describe below that the transparent Schottky contact fabricated by TCP is applicable not only to the photovoltaic device but also to defect density investigation. Nakano et al. applied deep-level optical spectroscopy (DLOS) to the PANI/epi.-GaN samples (Nakano et al., 2010, 2011a, 2011b). DLOS allows the deep-level density in semiconductors to be estimated by detecting the change in capacitance, which is caused by discharging the deeplevels by exciting electrons with monochromatic light. The measurement process was as 
follows. The residual electrons in the deep levels were excluded by applying a reverse bias $(-2 \mathrm{~V})$ and extending the depletion layer. Then, the bias was removed for 1 second to fill the deep levels with electrons in the dark. After that, the same reverse bias was again applied to form the depletion layer followed by monochromatic light illumination that excites electrons in the deep levels up to the conduction band. The difference in the capacitance between the filled state and post-excited states (discharged) was detected as $\Delta C$. The density of the deeplevels is estimated by $2 N_{D} \Delta C / C_{\mathrm{i}}$, where $N_{D}$ is the donor concentration and $C_{\mathrm{i}}$ is the initial capacitance that is obtained in the filled state in the dark. Figure 7 shows the resulting DLOS spectra. Interestingly, both the spectra acquired at 1 and $10 \mathrm{kHz}$ bias frequency show no characteristic peaks; however, when the bias frequency was increased to $100 \mathrm{kHz}$, several peaks appeared in the spectrum. This specific frequency, $100 \mathrm{kHz}$, corresponds to the point where the total capacitance dropped down to a negligible level compared to the capacitance at 1 and $10 \mathrm{kHz}$. This means that the $C_{\mathrm{i}}$ became smaller comparable to $\Delta C$, thus, $2 N_{D} \Delta C / C_{\mathrm{i}}$ is effectively enhanced enough to be detectable.

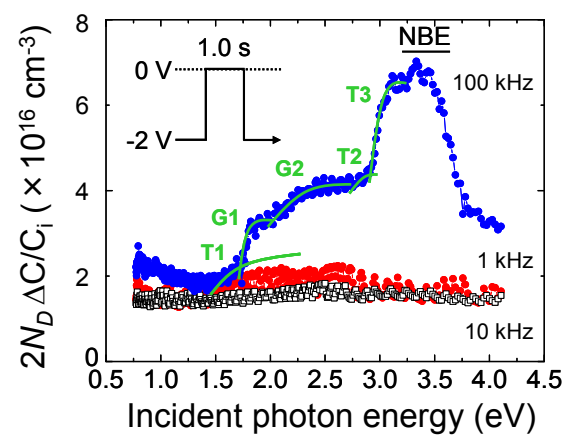

Fig. 7. DLOS spectra of PANI/epi.-GaN heterojunction solar cell.

In Figure 7, five photoemission states are clearly revealed with onsets at $\sim 1.40, \sim 1.70, \sim 2.08$, $\sim 2.64$, and $2.90 \mathrm{eV}$ below the conduction band, which are denoted as T1, G1, G2, T2, and T3, in addition to the near-band-edge (NBE) emissions of $\mathrm{GaN}$ at 3.3-3.5 eV. For all the deep levels, electron emission to the conduction band is a dominant process due to their positive photocapacitance transients. The T1, T2, and T3 levels are identical to the deep-level defects that have been commonly reported for GaN, whereas the G1 and G2 levels look like the specific deep levels characteristic of $\mathrm{AlGaN} / \mathrm{GaN}$ heterointerfaces that were reported recently (Nakano et al., 2008). Using the TCP Schottky contact, we successfully revealed the deep-level states in the near-surface region of the $n-G a N$ layer. These experimental results and further detailed investigations can provide important information on the electronic properties that is needed to improve the performance of the device in optical and electronic fields.

\subsection{Future perspective of TCP/nitride semiconductor heterojunction solar cells}

In order to increase the output power of $\mathrm{TCP} /$ nitride semiconductor heterojunction solar cells, the nitride portion is required to be substituted from $\mathrm{GaN}$ to $\operatorname{In}_{x} \mathrm{Ga}_{1-\mathrm{x}} \mathrm{N}$. The presumed difficulty in developing the TCP $/ n-\mathrm{In}_{x} \mathrm{Ga}_{1-x} \mathrm{~N}$ heterojunction is the lowering of the barrier height since the electron affinity significantly increases with an increase of the In content. 
One of the most plausible solutions for this issue is to insert a several-tens-nanometer-thick GaN or AIN layer between TCP and $n-\mathrm{In}_{x} \mathrm{Ga}_{1-x} \mathrm{~N}$. With this device structure, it is expected that the barrier height at the $\mathrm{TCP} /$ nitride semiconductor interface will be maintained at a high value and an internal electric field should be formed.

The cost of the sapphire substrate will become a high barrier for reducing the production cost of III-nitride based solar cells. Matsuki et al. have shown that high quality GaN can be grown on mica plates (Matsuki et al., 2005), which are inexpensive and flexible. Applying such a novel alternative to sapphire for the epitaxial growth substrate will be effective for developing large area $\mathrm{TCP} /$ nitride semiconductor heterojunction solar cells.

TCPs have a high transparency from $250 \mathrm{~nm}$ to the visible wavelength region, as described in section 5.1. Thus TCP/nitride semiconductor heterojunction photovoltaic devices also have a high potential for applications in ultraviolet sensors.

\section{Conclusion}

We have fabricated TCP/nitride semiconductor heterojunction solar cell structures by the spin-coating method using PEDOT:PSS or PANI as the TCP layer and Si-doped GaN as the semiconductor layer. The devices exhibited high quality rectifying properties and have an approximately $1 \mathrm{eV}$ barrier height. Both the PANI/epi.-GaN and PEDOT:PSS/epi.-GaN heterojunction solar cells exhibited ultraviolet-sensitive photovoltaic action. The observed open-circuit voltage was superior to previously reported values for metal/GaN Schottky photo-detectors. A characteristic frequency-dependent behaviour of the interface capacitance was found for the TCP/epi.-GaN solar cells. The $C-f$ characteristics were analyzed based on the dielectric dispersion theory and the intrinsic capacitance and resistance were obtained. The considerable reduction of the interface capacitance in the high frequency region allowed for highly-sensitive detection of deep levels in GaN by DLOS measurements.

\section{Acknowledgments}

The authors wish to acknowledge collaborations and discussions with Professor Michio Kondo, Dr. Takuya Matsui, Dr. Kenji Itaka, Professor Shunro Fuke, and Professor Hideomi Koinuma. This study was partially supported by the New Energy and Industrial Technology Development Organization (NEDO) Project, Research and Development on Innovative Solar Cells.

\section{References}

Bolto, B. A., McNeill, R., \& Weiss, D. E. (1963). Electronic conduction in polymers III. Electronic properties of polypyrrole, Australian Journal of Chemistry, Vol. 16, No. 5, (June 1963), pp. 1090-1103, ISSN 0004-9425

Brown, T. M., Kim, J. S., Friend, R. H., Cacialli, F., Daik R., \& Feast, W. J. (1999). Built-in field electroabsorption spectroscopy of polymer light-emitting diodes incorporating a doped poly(3,4-ethylene dioxythiophene) hole injection layer, Applied Physics Letters, Vol. 75, No. 12, (July 1999), pp. 1679-1681, ISSN 0003-6951

Chang, C. S., Chang, S. J., Su Y. K., Lin, Y. C., Hsu Y. P., Shei, S. C., Chen, S. C., Liu C. H., \& Liaw U. H. (2003). InGaN/GaN light-emitting diodes with ITO p-contact layers 
prepared by RF sputtering, Semiconductor Science and Technology, Vol. 18, No. 4, (February 2003), pp. L21-L23, ISSN 1361-6641

Chen, X., Matthews, K. D., Hao, D., Schaff, W. J., \& Eastman, L. F. (2008). Growth, fabrication, and characterization of InGaN solar cells, Physica Status Solidi (a), Vol. 205, No. 5, (July 2003), pp. 1103-1105, ISSN 1862-6300

Crowell, C. R. (1965). The Richardson constant for thermionic emission in Schottky barrier diodes, Solid-State Electronics, Vol. 8, No. 4, (April 1965), pp. 395-399, ISSN 00381101

Cole, K. S. \& Cole, R. H. (1941). Dispersion and absorption in dielectrics I. Alternating current characteristics, J. Chem. Phys., Vol. 9, No. 4, (April 1941), pp. 341-351, ISSN 0021-9606

Dahal, R., Pantha, B., Li. J., Lin, J. Y., \& Jiang, H. X. (2009). InGaN/GaN multiple quantum well solar cells with long operating wavelengths, Applied Physics Letters, Vol. 94, No. 6, (February 2009), pp. 063505-1-063505-3-1693, ISSN 0003-6951

Grabowski, S. P., Schneider, M., Nienhaus, H., Mönch, W., Dimitrov, R., Ambacher, O., \& Stutzmann, M. (2001). Electron affinity of $\mathrm{Al}_{\mathrm{x}} \mathrm{G}_{\mathrm{a} 1-\mathrm{x}} \mathrm{N}(0001)$ surfaces, Applied Physics Letters, Vol. 78, No. 17, (April 2001), pp. 2503-2505, ISSN 0003-6951

Green, M. A., Emery, K., Hishikawa, Y., \& Warta, W. (2010). Solar cell efficiency tables (version 37). Progress in Photovoltaics: Research and Applications, Vol. 19, No. 1, (December 2010), pp. 84-92, ISSN 1099-159X

Green, M. A. (2001). Third generation photovoltaics: Ultra-high conversion efficiency at low cost. Progress in Photovoltaics: Research and Applications, Vol. 9, No. 2, (December 2010), pp. 123-125, ISSN 1099-159X

Ha, Y. H., Nikolov, N., Pollack, S. K., Mastrangelo, J., Martin, B. D., \& Shashidhar, R. (2004). Towards a transparent, highly conductive poly(3, 4-ethylenedioxythiophene), Advanced Functional Materials, Vol. 14, No. 6, (June 2004), pp. 615-622, ISSN 1616$301 X$

Heeger J. A. (2001). Nobel Lecture: Semiconducting and metallic polymers: The fourth generation of polymeric materials, Review of Modern Physics, Vol. 73, No. 3, (July 2001), pp. 681-700, ISSN 0034-6861

Jang J., Ha, J., \& Kim, K. (2008). Organic light-emitting diode with polyaniline-poly(styrene sulfonate) as a hole injection layer, Thin Solid Films, Vol. 516, No. 10, (August 2007), pp. 3152-3156, ISSN 1616-301X

Kampen, T. U. (2006). Electronic structure of organic interfaces - a case study on perylene derivatives, Applied Physics A, Vol. 82, No. 3, (September 2005), pp. 457-470, ISSN 0947-8396

Kane, E. O. (1962). Theory of Photoelectric Emission from Semiconductors, Physical Review, Vol. 127, No. 1, (July 1962), pp. 131-141, ISSN 1943-2879

Kim, J. K., Jang, H. W., Jeon, C. M., \& Lee, J.-L. (2002). GaN metal-semiconductor-metal ultraviolet photodetector with $\mathrm{IrO}_{2}$ Schottky contact, Applied Physics Letters, Vol. 81, No. 24, (December 2002), pp. 4655-4657, ISSN 0003-6951

Kuwahara, Y., Takahiro F.; Yasuharu, F.; Sugiyama, T.; Iwaya, M.; Takeuchi, T.; Kamiyama, S.; Akasaki, I.; \& Amano, H. (2010). Realization of nitride-based solar cell on freestanding GaN substrate, Applied Physics Express, Vol. 3, No. 11, (October 2010), pp. 111001-1-111001-3, ISSN 1882-0778 
Kuwahara, Y., Takahiro, F., Sugiyama, T., Iida, D., Isobe, Y., Fujiyama, Y., Morita, Y., Iwaya, M., Takeuchi, T., Kamiyama, S., Akasaki, I., \& Amano, H. (2011). GaInN-based solar cells using strained-layer GaInN/GaInN superlattice Active Layer on a Freestanding GaN Substrate, Applied Physics Express, Vol. 4, No. 2, (January 2011), pp. 021001-1-021001-3, ISSN 1882-0778

Lee, K., Cho, S., Park, S.-H., Heeger, A. J., Lee, C.-W., \& Lee, S.-H. (2006). Metallic transport in polyaniline, Nature, Vol. 441, (4 May 2006), pp. 65-68, ISSN 0028-0836

Mathai, C. J., Saravanan, S., Anantharaman, M. R., Venkitachalam, S., \& Jayalekshmi, S. (2002). Characterization of low dielectric constant polyaniline thin film synthesized by ac plasma polymerization technique, J. Phys. D: Applied Physics, Vol. 35, No. 3, (January 2002), pp. 240-245, ISSN 0022-3727

Matsuki, N., Kim, T.-W., Ohta, J., \& Fujioka, H. (2005). Heteroepitaxial growth of gallium nitride on muscovite mica plates by pulsed laser deposition, Solid State Communications, Vol. 136, No. 6, (August 2005), pp. 338-341, ISSN 0038-1098

Matsuki, N., Irokawa, Y., Matsui, T., Kondo, M., \& Sumiya, M. (2009). Photovoltaic Action in Polyaniline/n-GaN Schottky Diodes, Applied Physics Express, Vol. 2, No. 9, (August 2009), pp. 092201-1-092201-3, ISSN 1882-0778

Matsuki, N., Irokawa Y., Nakano Y., \& Sumiya M. (2010). $\pi$-Conjugated polymer/GaN Schottky solar cells, Solar Energy Materials \& Solar Cells, Vol. 95, No. 9, (May 2010), pp. 284-287, ISSN 0927-0248

Matsuki, N., Irokawa Y., Nakano Y., \& Sumiya M. (2011). Heterointerface properties of novel hybrid solar cells consisting of transparent conductive polymers and IIInitride semiconductors, Journal of Nonlinear Optical Physics \& Materials, Vol. 19, No. 4, (December 2010), pp. 703-711, ISSN 0218-8635

Matsuoka, T., Okamoto, H., Nakano, M., Harima, H., \& Kurimoto, E. (2002). Optical bandgap energy of wurtzite InN, Applied Physics Letters, Vol. 81, No. 7, (June 2002), pp. 1246-1248, ISSN 0003-6951

Mott, N. F. (1939). The theory of crystal rectifiers, Proceedings of the Royal Society, Vol. 171, No. 944, (May 1939), pp. 27-38, ISSN 364-5021

Myers, D. R., Kurtz, S. R., Whitaker, C., \& Townsend, T. (2000). Preliminary investigations of outdoor meteorological broadband and spectral conditions for evaluating photovoltaic modules and systems. Program and Proceedings: NCPV Program Review Meeting 2000, 16-19 April 2000, Denver, Colorado. BK-520-28064. Golden, CO: National Renewable Energy Laboratory; pp. 69-70; NREL Report No. CP-560-28187

Nakano, M., Makino, T., Tsukazaki, A., Kazunori U., Ohtomo, A., Fukumura, T., Yuji, H., Nishimoto, Y., Akasaka, S., Takamizu, D., Nakahara, K., Tanabe, T., Kamisawa, A., \& Kawasaki M. (2007). $\mathrm{Mg}_{x} \mathrm{Zn}_{\mathrm{x}} \mathrm{O}$-based Schottky photodiode for highly colorselective ultraviolet light detection, Applied Physics Letters, Vol. 91, No. 14, (October 2007), pp. 142113-1-142113-3, ISSN 0003-6951

Nakano, M., Makino, T., Tsukazaki, A., Ueno K., Ohtomo, A., Fukumura, T., Yuji H., Akasaka, S., Tamura, K., Nakahara, K., Tanabe, T., Kamisawa, A., \& Kawasaki, M. (2008). Transparent polymer Schottky contact for a high performance visible-blind ultraviolet photodiode based on ZnO, Applied Physics Letters, Vol. 93, No. 12, (December 2008), pp. 123309-1-123309-3, ISSN 0003-6951 
Nakano, Y., Irokawa, Y., \& Takeguchi M. (2008). Deep-level optical spectroscopy investigation of band gap states in AlGaN/GaN hetero-interfaces, Applied Physics Express, Vol. 1, No. 9, (August 2008), pp. 091101-1-091101-3, ISSN 1882-0778

Nakano, Y., Matsuki, N., Irokawa, Y., \& Sumiya, M. (2010). Electrical characterization of nGaN epilayers using transparent polyaniline Schottky contacts, Physica Status Solidi C, Vol. 7, No. 7-8, (April 2010), pp. 2007-2009, ISSN 1610-1634

Nakano, Y., Matsuki, N., Irokawa, Y., \& Sumiya, M. (2011a). Deep-level characterization of n-GaN epitaxial layers using transparent conductive polyaniline Schottky contacts, Japanese Journal of Applied Physics, Vol. 50, No. 1, (January 2011), pp. 01AD02-101AD02-4, ISSN 0021-4922

Nakano, Y., Lozac'h, M., Matsuki, N., Sakoda, K., \& Sumiya, M. (2011b). Photocapacitance spectroscopy study of deep-level defects in freestanding $n-G a N$ substrates using transparent conductive polymer Schottky contacts, Journal of Vacuum Science and Technology B, Vol. 29, No. 2, (January 2011), pp. 023001-1- 023001-4, ISSN 1071-1023

Satoh, K., Kakehi, Y., Okamoto, A., Murakami, S., Moriwaki, K., \& Yotsuya, T. (2007). Electrical and optical properties of Al-doped $\mathrm{ZnO}-\mathrm{SnO}_{2}$ thin films deposited by $\mathrm{RF}$ magnetron sputtering, Thin Solid Films, Vol. 516, No. 17, (October 2007), pp. 58145817, ISSN 1616-301X

Schottky, W. (1939). Zur Halbleitertheorie der Sperrschicht- und Spitzengleichrichter (The semiconductor theory of the barrier layer rectifiers and tip rectifiers), Zeitschrift für Physik, Vol. 113, No. 5-6, (May 1939), pp. 367-414, ISSN $0939-7922$

Shirakawa, H., Edwin L., MacDiamid, A. G., Chiang, C., \& Heeger, A. (1977). Synthesis of electrically conducting organic polymers: halogen derivatives of polyacetylene, (CH), Journal of the Chemical Society, Chemical Communications, No. 16, (May 1977), pp. 578-580, ISSN 0022-4936

Shim, K.-H., Paek, M.-C., Lee, B. T., Kim C., \& Kang J. Y. (2001). Preferential regrowth of indium-tin oxide (ITO) films deposited on GaN(0001) by rf-magnetron sputter, Applied Physics A, Vol. 72, No. 1, (February 2001), pp. 471-474, ISSN 0947-8396

da Silva, W. J., Hümmelgen, I. A., \& Mello, R. M. Q. (2009). Sulfonated polyaniline/n-type silicon junctions, Journal of Material Science: Materials in Electronics, Vol. 20, No. 2, (February 2009), pp. 123-126, ISSN 0022-2461

Solomon, S., Qin, D., Manning, M., Chen, Z., Marquis, M., Averyt, K., Tignor M. B. M., \& Miller Jr., H. L. (Ed.). (2007). Climate Change 2007, The Physical Science Basis, Contribution of Working Group I to the Fourth Assessment Report of the IPCC, ISBN 9780521 88009-1

Song, J. O., Ha, J.-S., \& Seong, T.-Y. (2010). Ohmic-contact technology for GaN-based lightemitting diodes: Role of p-type contact, IEEE Transactions on Electron Devices, Vol. 57, No. 1, (January 2010), pp. 42-59, ISSN 0018-9383

Sze, S. M. (1981). Physics of Semiconductor Devices, Wiley Interscience Publication, ISBN 0471-05661-8, New York, USA

Takeuchi, T., Wetzel, C., Yamaguchi, S., Sakai, H., Amano, H., \& Akasaki I. (1998). Determination of piezoelectric fields in strained GaInN quantum wells using the quantum-confined Stark effect. Applied Physics Letters, Vol. 73, No. 12, (July 1998), pp. 1691-1693, ISSN 0003-6951

Tracy, K. M., Hartlieb P. J., Einfeldt, S., Davis, R. F., Hurt, E. H., \& Nemanich, R. J. (2003). Electrical and chemical characterization of the Schottky barrier formed between 
clean n-GaN (0001) surfaces and Pt, Au, and Ag, Journal of Applied Physics, Vol. 94, No. 6, (September 2003), pp. 3939-3948, ISSN 0021-8979

Tung, R. T. (2001). Recent advances in Schottky barrier concepts, Material Science and Engineering B, Vol. 35, No. 1-3, (November 2001), pp. 1-138, ISSN 0921-5107

Wang, W. \& Schiff, E. A. (2007). Polyaniline on crystalline silicon heterojunction solar cells, Applied Physics Letters, Vol. 91, No. 13, (September 2007), pp. 133504-1-133504-3, ISSN 0003-6951

Wu, C.I. \& Kahn, A. (1999). Electronic states and effective negative electron affinity at cesiated p-GaN surfaces, Journal of Applied Physics, Vol. 86, No. 6, (September 1999), pp. 3209-3212, ISSN 0021-8979

Wu, J., Walukiewicz, W., Shan, W., Yu, K. M., Ager, J. W., Li, S. X., Haller, E. E., Lu, H., \& Schaff, W. J. (2003). Temperature dependence of the fundamental band gap of InN, Journal of Applied Physics, Vol. 94, No. 7, (July 2003), pp. 4457-1260, ISSN 1089-7550

Wu, J., Walukiewicz. W, Li., S. X., Armitage, R., Ho, J. C., Weber, E., R., Haller, E. E., Lu, H. Schaff, W. J., Barcz, A. \& Jakieka R. (2004). Effects of electron concentration on the optical absorption edge of InN, Applied Physics Letters, Vol. 84, No. 15, (April 2004), pp. 2805-2807, ISSN 0003-6951

$\mathrm{Wu}, \mathrm{J}$. (2009). When group-III nitrides go infrared: New properties and perspectives, Journal of Applied Physics, Vol. 106, No. 1, (July 2009), pp. 011101-1-011101-28, ISSN 00218979

Yamaguchi, M. (2003). III-V compound multi-junction solar cells: present and future, Solar Energy Materials \& Solar Cells, Vol. 75, No. 1-2, (April 2003), pp. 261-269, ISSN 09270248

Yamaura, J., Muraoka, Y., Yamauchi, T., Muramatsu, T., \& Hiroi, Z. (2003). Ultraviolet light selective photodiode based on an organic-inorganic heterostructure, Applied Physics Letters, Vol. 83, No. 11, (July 2003), pp. 2097-2099, ISSN 0003-6951

Zheng X., Horng, R.-H., Wuu, D.-S., Chu, M.-T., Liao, W.-Y., Wu, M.-H., Lin, R.-M., \& Lu, Y.-C. (2008). Applied Physics Letters, Vol. 93, No. 26, (December 1998), pp. 261108-1261108-3, ISSN 0003-6951

Zhou, Y., Ahyi, C., Tin, C.-C., Williams, J., Park, M., Kim, D.-J., Cheng, A.-J., Wang D., Hanser, A., Edward, A. P., Williams, N. M., \& Evans K. (2007). Fabrication and device characteristics of Schottky-type bulk GaN-based "visible-blind" ultraviolet photodetectors, Applied Physics Letters, Vol. 90, No. 12, (March 2007), pp. 121118-1121118-3, ISSN 0003-6951 


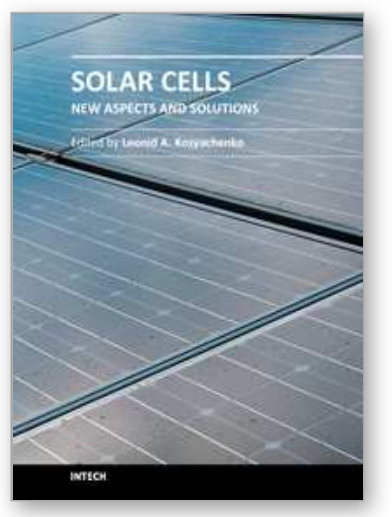

\author{
Solar Cells - New Aspects and Solutions \\ Edited by Prof. Leonid A. Kosyachenko
}

ISBN 978-953-307-761-1

Hard cover, 512 pages

Publisher InTech

Published online 02, November, 2011

Published in print edition November, 2011

The fourth book of the four-volume edition of 'Solar cells' consists chapters that are general in nature and not related specifically to the so-called photovoltaic generations, novel scientific ideas and technical solutions, which has not properly approved. General issues of the efficiency of solar cell and through hydrogen production in photoelectrochemical solar cell are discussed. Considerable attention is paid to the quantum-size effects in solar cells both in general and on specific examples of super-lattices, quantum dots, etc. New materials, such as cuprous oxide as an active material for solar cells, AlSb for use as an absorber layer in $p$-i-n junction solar cells, InGaAsN as a promising material for multi-junction tandem solar cells, InP in solar cells with MIS structures are discussed. Several chapters are devoted to the analysis of both status and perspective of organic photovoltaics such as polymer/fullerene solar cells, poly( $p$-phenylene-vinylene) derivatives, photovoltaic textiles, photovoltaic fibers, etc.

\title{
How to reference
}

In order to correctly reference this scholarly work, feel free to copy and paste the following:

Nobuyuki Matsuki, Yoshitaka Nakano, Yoshihiro Irokawa, Mickael Lozac'h and Masatomo Sumiya (2011). Transparent Conducting Polymer/Nitride Semiconductor Heterojunction Solar Cells, Solar Cells - New Aspects and Solutions, Prof. Leonid A. Kosyachenko (Ed.), ISBN: 978-953-307-761-1, InTech, Available from: http://www.intechopen.com/books/solar-cells-new-aspects-and-solutions/transparent-conducting-polymernitride-semiconductor-heterojunction-solar-cells

\section{INTECH}

open science | open minds

\section{InTech Europe}

University Campus STeP Ri

Slavka Krautzeka 83/A

51000 Rijeka, Croatia

Phone: +385 (51) 770447

Fax: +385 (51) 686166

www.intechopen.com

\section{InTech China}

Unit 405, Office Block, Hotel Equatorial Shanghai

No.65, Yan An Road (West), Shanghai, 200040, China

中国上海市延安西路65号上海国际贵都大饭店办公楼405单元

Phone: +86-21-62489820

Fax: $+86-21-62489821$ 
(C) 2011 The Author(s). Licensee IntechOpen. This is an open access article distributed under the terms of the Creative Commons Attribution 3.0 License, which permits unrestricted use, distribution, and reproduction in any medium, provided the original work is properly cited. 